\title{
Das Mobilizações à Política de Educação das Relações Étnico-raciais
}

\author{
GUIMARÃES, Carlos Augusto Sant'Anna'
}

\section{RESUMO}

O presente artigo examina episódios e iniciativas que possibilitaram o agendamento do combate ao racismo e outras demandas do Movimento Negro brasileiro no final do século $\mathrm{XX}$, culminando na política de promoção da igualdade racial. $O$ texto debruça-se em especial sobre a política de educação para as relações étnico-raciais. Uma inovação institucional em termos de política curricular. $O$ aporte teórico alicerça-se na teoria do processo político, no modelo dos múltiplos fluxos e no debate sobre federalismo. A análise efetivou-se mediante o esquadrinhamento de fontes secundárias: a produção acadêmica disponível (artigos, teses e dissertações) e documentos públicos (legislação e planos de elaborados pelos agentes públicos e documentos produzidos pelo Movimento Negro). Os resultados evidenciam que a implementação da política de educação para as relações raciais enfrenta óbices de natureza institucional e política, como, por exemplo, a ausência de uma estrutura de incentivos que promova a adesão dos entes federativos, além de, sobretudo, deparar com o que pretende destruir: o próprio racismo nas mais distintas facetas.

\section{Agendamento. Relações Étnico-Raciais. Política Curricular. Inovação Institucional.}

\section{From Mobilizations to the Education Policy of Ethnic-Racial Relations}

\section{ABSTRACT}

This article examines episodes and initiatives that enabled the topic of fighting racism and other demands from the Brazilian Black Movement to be placed on the agenda in the late 20th century, culminating in policy to promote racial equality. The paper addresses education policy for ethnic-racial relations. This was an institutional innovation in terms of curricular policy. The theoretical contribution is based on political process theory, the multiple flow model and the debate on federalism. The analysis was conducted by investigating secondary sources: the academic production available (articles, theses and dissertations) and public documents (legislation and plans prepared by public officials and

\footnotetext{
${ }^{1}$ Doutor em Ciência Política pela Universidade Estadual de Campinas (Unicamp). Pesquisador assistente na Diretoria de Pesquisas Sociais da Fundação Joaquim Nabuco. E-mail: carlos.santanna@fundaj.gov.br. Lattes: http://lattes.cnpq.br/2463742072275540. Orcid: https://orcid.org/0000-0002-5802-0181 ?lang=pt.
}

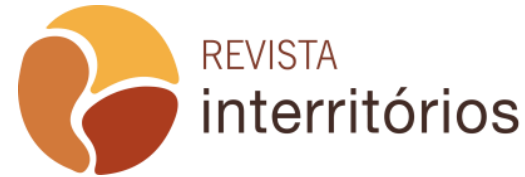


documents produced by the Black Movement). The results demonstrate that the introduction of education policy for racial relations faces obstacles of an institutional and political nature, such as the absence of a structure of incentives that promotes adherence by the federative units, and, above all, encountering what it intends to destroy: the distinctive aspects of racism.

\section{Agenda Setting. Ethnic/Racial Relations. Curricular Policy. Institutional Innovation.}

\section{De las movilizaciones a la política educativa de las relaciones étnico-raciales}

\section{RESUMEN}

Este artículo analiza episodios e iniciativas que permitieron poner en la agenda la lucha contra el racismo y otras demandas del Movimiento Negro Brasileño a fines del siglo XX, culminando con la política de promoción de la igualdad racial. El texto se centra en particular en la política de educación para las relaciones étnico-raciales. Una innovación institucional en términos de política curricular. El aporte teórico se basa en la teoría del proceso político, en el modelo de múltiples flujos y en el debate sobre el federalismo. El análisis se llevó a cabo mediante el escaneo de fuentes secundarias: la producción académica disponible (artículos, tesis y disertaciones) y documentos públicos (legislación y planes elaborados por agentes públicos y documentos elaborados por el Movimiento Negro). Los resultados muestran que la implementación de la política de educación para las relaciones raciales enfrenta obstáculos de carácter institucional y político como, por ejemplo, la ausencia de una estructura de incentivos que promueva la adhesión de entidades federativas, además de, sobre todo, encontrar con que pretende destruir: el racismo mismo en las más diversas facetas.

\section{Agendamiento. Relaciones Étnico-Raciales. Política Curricular. Innovación institucional.}

\section{Dalle mobilitazioni alla politica educativa dei rapporti etnico-razziali}

\section{SOMMARIO}

Questo articolo analizza episodi e iniziative che hanno permesso di mettere all'ordine del giorno la lotta al razzismo e altre rivendicazioni del Movimento nero brasiliano alla fine del XX secolo, culminando nella politica di promozione dell'uguaglianza razziale. II testo si concentra in particolare sulla politica di educazione alle relazioni etnico-razziali. Un'innovazione istituzionale in termini di politica curricolare. II contributo teorico si basa sulla teoria del processo politico, nel modello dei flussi multipli e nel dibattito sul federalismo. L'analisi è stata condotta scansionando fonti secondarie: produzione accademica disponibile (articoli, tesi e dissertazioni) e documenti pubblici (legislazione e piani preparati da agenti pubblici e documenti preparati dal Movimento Nero). I risultati mostrano

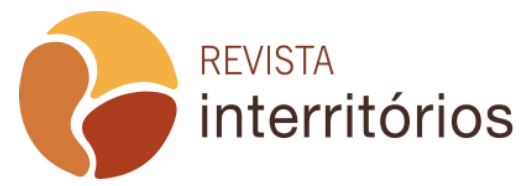

Interritórios | Revista de Educação Universidade Federal de Pernambuco, Caruaru, BRASIL | V.6 N.12 [2020] 
che l'attuazione della politica educativa per le relazioni razziali incontra ostacoli di natura istituzionale e politica come, ad esempio, l'assenza di una struttura di incentivi che promuova l'adesione degli Stati, oltre, soprattutto, l'incontro che mira a distruggere: il razzismo stesso nelle più diverse sfaccettature.

Pianificazione. Relazioni etnico-razziali. Politica curricolare. Innovazione istituzionale.

\section{INTRODUÇÃO}

Contrariamente ao que supõe o senso comum, políticas públicas não resultam de uma decisão instantânea na cúpula do Estado, dependente da "vontade política" do chefe do Executivo, tampouco um processo linear e coerente. Longe disso, são processos complexos, ambíguos e multifacetados. Geralmente conflituosos, envolvem disputas de crenças e valores; constrangimentos materiais, institucionais e simbólicos; são lócus de acordos e negociações entre atores sociais e políticos; assim como espaços de criatividade, inovação e experimentação.

O tema das desigualdades raciais alcançou a agenda governamental, em 1995, após a Marcha Zumbi dos Palmares contra o Racismo, pela Cidadania e pela Vida, inspirada na célebre Marcha sobre Washington por Trabalho e Liberdade, em 1963, na capital dos Estados Unidos, naquela que foi a maior manifestação do Movimento dos Direitos Civis. A versão brasileira teve como palco Brasília e reuniu, naquele 20 de novembro, mais de 30 mil manifestantes. Após o evento, o presidente Fernando Henrique Cardoso assinou decreto criando o Grupo de Trabalho Interministerial para a Valorização da População Negra, conhecido como GTI. Esse grupo reunia membros do governo federal e pessoas indicadas pelo Movimento Negro, com a missão de elaborar propostas visando à valorização social e ao desenvolvimento econômico da população negra brasileira.

Logo em seguida, em 2001, houve a realização da 3ª Conferência Mundial contra o Racismo, a Discriminação Racial, a Xenofobia e a Intolerância Correlata, organizada pela Organização das Nações Unidas (ONU), realizada na cidade de Durban, África do Sul, com importantes repercussões no Brasil, assinalando o início de uma nova fase no tratamento da questão racial.

No primeiro mês das gestões petistas à frente do Poder Executivo federal, o Congresso Nacional aprovou a Lei no 10.639/2003, que modificou o Artigo 26a da Lei de Diretrizes e Bases da Educação Nacional (LDBEN), Lei no 9.394/1996, que determinava obrigatoriedade do ensino de História da África e cultura afrobrasileira em todos os níveis e modalidades de ensino da educação básica, em 
escolas públicas e privadas. ${ }^{2}$ Pouco depois, era criada a Secretária Especial de Promoção de Políticas de Igualdade Racial (SEPPIR) e, na sequência, lançada a Política Nacional de Promoção da Igualdade Racial (PNPIR).

Em um primeiro e desatento olhar, essas inovações institucionais podem ser interpretadas como produto da "vontade política" do Governo Lula (20032010) em saldar a dívida histórica com a população negra. Denotariam um compromisso político-programático do Partido dos Trabalhadores (PT), em modificar os termos (sentido e direção) da "política racial" brasileira. Não há dúvida de que com o PT o tema alcançou a agenda decisória de governo. ${ }^{3}$ Sem embargo, para uma melhor compreensão do processo, é mister reconstituir a trajetória, relembrar os principais episódios até à aprovação da referida lei, criação da SEPPIR e elaboração da PNPIR.

Neste trabalho, debruço-me sobre as mudanças introduzidas na LDBEN, centrando-me em alguns aspectos da sua implementação. Este artigo é um dos produtos da minha Tese de Doutorado, na qual analisei a atuação do Movimento Negro na mudança institucional produzida pela Política de Promoção da Igualdade Racial, no âmbito municipal. Aqui, analiso os acontecimentos e iniciativas que possibilitaram a incorporação de demandas históricas do Movimento Negro em políticas públicas, mirando especificamente para o campo educacional, mais precisamente os seus desdobramentos (institucionalização e implementação das Leis 10.639/2003 e 11. 645/2008). Examino documentos públicos (legislação e planos elaborados pelo poder público, bem como textos produzidos pelo Movimento Negro) e a produção acadêmica sobre o tema.

Como o Movimento Negro inscreveu a problemática racial na agenda governamental, posto ser um tema interdito? Sabe-se que, "no Brasil, não é de bom tom 'puxar assunto de cor', diante de uma pessoa preta ou parda (...) Em contraposição, em qualquer contenda com uma pessoa de cor, a primeira ofensa que se lhe assaca é a referência à sua origem étnica." (NOGUEIRA, 2006, p. 299). Do ponto de vista teórico, a questão coloca-se nos seguintes termos: quando e como um tópico ascende à agenda governamental?

O esforço aqui não é o de descrever um fenômeno novo que ninguém viu ou percebeu, mas o de trazer uma nova interpretação sobre fatos e eventos, alguns deles já bastante debatidos, mas pouco problematizados e interpretados à luz de um arcabouço teórico de políticas públicas. Proponho uma mirada sobre o processo de agendamento da questão racial no nível federal de governo, discutindo a institucionalização e a implementação das diretrizes curriculares nacionais para a educação das relações étnico-raciais e para o ensino de história

\footnotetext{
2 Em 2008, a Lei no 11.645 determinou a obrigatoriedade do ensino de história e cultura indígena.

${ }^{3}$ Ver Kingdon (2014).
} 
e cultura afro-brasileira e africana, por meio da análise do plano nacional de implementação das referidas diretrizes.

A maioria dos estudos que enfocam o Movimento Negro o fazem sob as lentes da abordagem das relações raciais e, mais recentemente, mesclado com a teoria crítica do reconhecimento, ancorada, sobretudo na contribuição de Fraser (2001; 2007). Aqui, proponho um diálogo com a Teoria do Processo Político (TARROW, 2009), para compreender a agência do Movimento Negro, combinada com a Teoria dos Múltiplos Fluxos, de Kingdon (2014), para analisar o processo de agendamento da questão racial, bem como seus desdobramentos.

\section{Transformações recentes na política racial Brasileira}

Historicamente, o Estado brasileiro mostrou-se refratário e hostil às demandas da população negra por tratamento igualitário desde a abolição da escravatura, rechaçando qualquer iniciativa em reconhecer a prática e coibir o preconceito e a discriminação racial antinegro (JACCOUD; BEGHIN, 2002). Na realidade, o projeto nacional era o de branqueamento da população nacional via uma miscigenação contínua com o elemento branco, o que culminaria "no apagamento final da negritude e do indigenismo da nação" (HOLSTON, 2013, p. 105).

A partir da década de 1930, e, posteriormente, impulsionada pelo projeto UNESCO, nos anos de 1950, prosperou a crença sociológica de que a raça ou qualquer aspecto racial perderia relevância na sociedade por conta do processo de modernização, em função do desenvolvimento capitalista. Mas o idílio de Brasil branco soçobrou, pois, de acordo com os dados do Censo de 2010, a maioria da população brasileira declara-se não-branca (pretos, pardos e indígenas); 47,7 \% dos brasileiros afirmaram serem brancos (IBGE, 2010). O fato é que, em termos absolutos, o país detém a segunda maior população negra no mundo, atrás apenas da Nigéria, na África. O que se observa é que, raça se manteve como uma categoria de identificação social que estrutura as relações sociais, mesmo quando não acionada discursivamente.

Os indicadores sociais revelam o fosso social entre os grupos por raça/cor (IPEA, 2008). A desigualdade socioeconômica expressa no binômio marcado pela clivagem riqueza/branquidade e pobreza/negritude. Raça e classe social funcionam quase como sinônimos: brancos - ricos e classe média; negros pobres e miseráveis, quando não, má índole e perigo. Diante desse quadro, Pinto (2008) nos provoca a reflexão acerca do estatuto teórico do conceito do reconhecimento (FRASER, 2001; 2007) à luz do caso brasileiro com enorme déficit de bem-estar social, no qual, os estratos altos e médios não se veem 
iguais aos demais membros da sociedade, cuja maior parcela não se sente cidadã.

O argumento utilizado à direita e à esquerda, desde textos acadêmicos ao senso comum, é de que os negros são discriminados por serem pobres. $O$ Movimento Negro e especialistas do tema contra-argumentam que os negros são pobres porque são discriminados. Ou seja, a pobreza material é derivada do preconceito e da discriminação racial a que essa população está submetida. Daí o dever do Estado de prover políticas públicas de enfrentamento ao racismo, ao preconceito e à discriminação racial.

Antecedentes históricos: das mobilizações de ruas à política pública

Ao longo do seu curso, o Movimento Negro, principiados nos anos de 1930 com a criação da Frente Negra, tomou a educação escolar como um portal poderoso para ascensão social e empreendeu seus próprios processos de escolarização, quer seja de alfabetização da população negra adulta, quer sejam iniciativas destinadas à formação de crianças e adolescentes, mas sempre em pequena escala, além de reivindicar a expansão da escola pública para todos, nesse caso à população negra, em todos os níveis de ensino (SILVA, C, 2019).

Do ponto de vista da luta política, o Movimento Negro desempenha o papel de cobrar “(...) a plena consolidação da ordem social competitiva e do modelo correspondente de organização democrática das relações entre os homens" (FERNANDES, 2008, p. 9). Assim, o direito à educação pública e gratuita constituiu uma bandeira de luta prioritária e perene do Movimento Negro desde os primórdios do século XX.

Posteriormente, estudos e pesquisas educacionais evidenciaram que 0 espaço escolar é marcadamente discriminatório em relação às populações nãobrancas, redundando num aproveitamento desigual e exigindo-lhes maior empenho para alcançar o sucesso escolar (PAIXÃO, 2008). Desse modo, a bandeira da educação seria acrescida da preocupação de ser antirracista e descolonizadora de corações e mentes, tanto dos professores quanto dos educandos.

Após a extinção da Frente Negra, em 1937, o silenciamento do protesto negro, que perdurou por mais de 40 anos, período áureo da hegemonia da democracia racial, somente no final dos anos de 1970, como parte do fenômeno reemergência dos movimentos sociais (AVRITZER, 1994), o Movimento Negro irrompeu na forma de mobilizações de rua, questionando o mito da democracia racial. Naquela década, inúmeras organizações negras haviam sido criadas em diferentes cidades brasileiras, notadamente nas capitais (SANTOS, I, 2006; PEREIRA, 2008). Fruto dessas mobilizações, em julho de 1978, nas escadarias 
do Teatro Municipal de São Paulo, era lançado o Movimento Unificado Contra a Discriminação Racial. Somente, após reuniões de diversos grupos, decidiu-se incorporar a palavra negro, tornando-se Movimento Negro Unificado Contra a Discriminação Racial (PEREIRA, 2008). ${ }^{4}$

A proliferação de coletivos e organizações negras foi um dos efeitos não esperados da expansão do sistema educacional público, tanto secundário (ensino médio) quanto universitário, promovida pela ditadura militar amalgamada com as transformações de natureza social, cultural e econômica nos cenários doméstico e internacional. Por exemplo, a realização da 1aㅡ Conferência Mundial contra o Racismo, promovida pela ONU, em 1978, aliada às contradições inerentes à ideologia racial brasileira de que a ascensão social implicaria o fim do preconceito e da discriminação racial (HASENBALG, 1984; SANTOS, J, 1985).

A emersão do protesto negro, no final dos anos de 1970, intensificados nas décadas seguintes, é o sinal de que a estrutura de poder havia se tornado "flexível e vulnerável a investidas políticas dos grupos excluídos (EISINGER, 1973, p. 28). Segundo esse autor, as características do regime político impactam nas possibilidades de ações disruptivas por parte dos grupos excluídos do poder. Elas serão mais prevalentes em sistemas políticos que exibem um mix de variáveis de abertura e fechamento. Desse modo, regimes situados nos extremos - bastante fechados (repressivos) ou bastante abertos politicamente reduzem as chances de protestos.

O conceito de Estrutura de Oportunidades Políticas (EOP) remete-nos a um conjunto de variáveis que assume um formato de uma configuração causal curvilinear. Isto é, a emergência de ações de protestos resulta da interação dinâmica entre variáveis, mas que não assume uma relação linear entre elas. Em geral, "as oportunidades e restrições políticas são situacionais" (TARROW, 2009, p. 106-107), ou seja, são contingentes e não se relevam com a mesma intensidade, momento e extensão para todos os contestadores e detentores do poder.

Se, por um lado, uma EOP pode se apresentar como incentivos a ações coletivas de protestos, por outro, na medida em que é incerta, não há como predizer quando ocorrerá e se será favorável aos desafiantes do poder. Desse modo, só se pode conhecê-la mediante a experiência.

Tarrow (2009) identifica cinco dimensões relevantes da EOP: 1) abertura do acesso à participação para novos atores; 2) evidências de realinhamento político no interior do sistema; 3) aparecimento de aliados influentes; 4) divisões emergentes no interior da elite; 5) repressão ou facilitação da dissidência. Para

${ }^{4}$ Cf. Hanchard (2001); Pereira (2008). 
que uma EOP seja favorável a um movimento social, não é necessário que ocorra uma interação entre todas essas dimensões. Na realidade, dificilmente isso ocorre. Basta uma interação entre algumas daquelas variáveis. A teoria não precisa se uma dimensão tem maior poder de indução que outras ou se uma combinação seria mais forte que outras.

A crise da democracia racial faz parte da crise do regime militar. $\mathrm{Na}$ medida em que os antigos aliados do regime começam a engrossar as fileiras dos descontentes com a ditadura, passando a combatê-la, e como a repressão brutal aos protestos não pode ser mantida no mesmo nível, novos contestadores percebem a abertura de oportunidades políticas para se mobilizarem, saírem às ruas e apresentar suas queixas e reivindicações, inaugurando um ciclo de protestos (GAMSON; MEYER, 1996). ${ }^{5}$ Este "se configura a partir de EOPs, em que vários grupos se organizam para expressar publicamente seu descontentamento" (ALONSO, COSTA; MACIEL, 2008). Assim, a reemergência do Movimento Negro faz parte do ciclo de protestos pela redemocratização.

No ciclo de mobilizações pró-constituinte, o Movimento Negro promoveu a Convenção Nacional do Negro pela Constituinte, em 1986, em Brasília, na qual foi aprovada a Declaração de Brasília com as reivindicações do movimento para serem defendidas pelos candidatos comprometidos com a luta antirracista. Dentre as nove áreas prioritárias, constava a educação (RIBEIRO, 2014). Dois anos depois, ainda durante os trabalhos da constituinte, teve lugar, na cidade do Recife, em julho de 1988, o $8^{\circ}$ Encontro de Negros do Norte e Nordeste, com o tema "O Negro e a Educação". A preocupação central foi "questionar a negação da importância do negro na formação social brasileira, por meio dos órgãos oficiais de educação do País". ${ }^{6}$ Entre as proposições aprovadas, sobressaía a necessidade de introduzir o estudo de História da África nos currículos escolares e discutir o papel dos docentes na descolonização do ensino, considerando a aprendizagem pela prática cultural como elemento útil para promover o sucesso no processo de ensino/aprendizagem da população negra.

Na subsequência da promulgação da nova Carta constitucional federal, vieram as constituintes estaduais, que promulgaram suas respectivas Constituições, em 1989. No ano seguinte, os municípios aprovaram suas Leis Orgânicas. É importante destacar que em muitas Leis Orgânicas foram inscritos artigos nos quais a municipalidade deveria garantir o ensino de História da África e Cultura Afro-Brasileira. No entanto, tais artigos não foram incorporados pelos sistemas municipais de educação.

No início dos anos 1990, o Fórum de Entidades Negras de Pernambuco (FENEPE) propõe um projeto por uma educação antirracista ao então deputado

\footnotetext{
${ }^{5}$ Sobre Estrutura de Oportunidades, cf. Eisinger (1973); McAdam (1996); Tarrow (2009).

${ }^{6}$ NEGRO E EDUCAÇAO. Relatório do VIII Encontro dos Negros do Norte e Nordeste do Brasil. Recife: Movimento Negro Unificado, 1988.
} 
estadual Humberto Costa (PT), que o apresenta em 1993, na forma de projeto de lei, na Assembleia Legislativa de Pernambuco. Aprovado em plenário, sofreu veto do governador, por considerá-lo inconstitucional. Uma vez eleito deputado federal, em 1995, o parlamentar apresentou-o, desta vez como projeto de lei nacional, PL no 859/1995. ${ }^{7}$ Após dormitar por 8 anos, este PL foi reativado pelos parlamentares Esther Grossi (PT-RS) e Ben-Hur Ferreira (PT-MS), que o reapresentaram, sendo aprovado e sancionado pelo presidente da República em janeiro de 2003 (BATISTA, 2009).

A capital federal foi sacudida, em 1995, por uma ruidosa manifestação do Movimento Negro, que, com o objetivo de comemorar o tricentenário da imortalidade de Zumbi dos Palmares, realizou a "Marcha 300 Anos de Zumbi dos Palmares contra o Racismo, pela Cidadania e a Vida". O ponto alto dessa manifestação foi a entrega do documento "Por uma Política Nacional de Combate ao Racismo e a Desigualdade Racial", que continha as principais reivindicações do Movimento Negro, ao presidente da República.

O GTI denotava a intenção do governo de dar um novo tratamento ao tema. Após dois anos de funcionamento, produziu um documento contendo propostas de inclusão dos negros na sociedade brasileira. No entanto, o próprio governo federal não criou mecanismos para viabilizar a execução do plano. Inclusive, alguns ministros eram contrários e boicotaram a implementação das recomendações do GTI (TELLES, 2003). Na interpretação de Rios (2012), um dos problemas do GTI foi assumir a problemática das desigualdades raciais sem, no entanto, se desfazer da noção de democracia racial.

No âmbito da educação, deve-se mencionar que, à época, a pasta afeita ao tema formulou os Parâmetros Curriculares Nacionais (PCNs), em 1996, nos quais incluía a ideia de pluralidade cultural como um de seus temas transversais, ainda em uma perspectiva universalista de educação (GOMES, 2009).

Nesse curso, outro episódio de monta foi a $3^{\mathrm{a}}$ Conferência Mundial contra - Racismo, a Discriminação Racial, a Xenofobia e a Intolerância Correlata, promovida pela Organização das Nações Unidas (ONU), em Durban, África do Sul, em 2001, contando com expressiva participação da sociedade civil negra brasileira. Esse encontro tornou-se um marco na luta contra o racismo e a discriminação racial no mundo, de um modo geral, e no Brasil, em particular, uma vez que incentivou a formulação de políticas de promoção da igualdade racial nas três esferas de governo.

A Marcha e a $3^{\underline{a}}$ Conferência Mundial contra o Racismo (3 $3^{\underline{a}}$ CMR) foram eventos que, por um lado, deram um novo ânimo à luta antirracista e, por outro, modificaram a percepção da sociedade brasileira e, notadamente, de parte da

${ }^{7}$ Cf. em https://www.camara.leg.br/proposicoesWeb/fichadetramitacao?idProposicao=183552. 
burocracia federal acerca da problemática racial. Desde então, Estado e Movimento Negro estabeleceram um novo tipo de interação, um repertório mais colaborativo, mas nem por isso livre de tensões e permeados por conflitos.

$\mathrm{Na}$ esteira da 3a CMR, o governo federal elaborou propostas de Ações Afirmativas, tais como a criação de um fundo de reparação social para financiar políticas inclusivas e o Programa Nacional de Ações Afirmativas. Entretanto, apenas a adoção de cotas raciais na ocupação de cargos comissionados no Ministério do Desenvolvimento Agrário foi efetivamente executada. As demais proposições tiveram implementação pífia ou sequer saíram da fase de elaboração (HERINGER, 2006; TELLES, 2003). Destaque para o programa de ações afirmativas do Instituto Rio Branco, cujo objetivo é "ampliar as oportunidades de acesso aos quadros do Ministério das Relações Exteriores e incentivar e apoiar o ingresso de afrodescendentes na carreira de diplomata."8 Heringer (op. cit.) identificou, no período de 2001 a 2004, 69 ações de promoção da igualdade racial nas três esferas de governo, no setor privado e no terceiro setor.

O debate público encetado pela $3^{\text {a }} \mathrm{CMR}$ centralizou-se no tema das cotas para negros como forma de ingresso no ensino superior, mobilizando opiniões apaixonadas, tornando esse um dos assuntos mais polêmicos, dominando a pauta jornalística nacional por meses. ${ }^{9}$

A partir de 2003, o tema ganhou um ímpeto extraordinário. A alteração da LDBEN contida na Lei o 10.639 foi bastante comemorada pelo Movimento Negro e por todos os defensores de uma educação antirracista, uma vez que, além da inclusão dos currículos de história africana e cultura afro-brasileira, pela primeira vez a história dos africanos e dos afrodescendentes receberia um tratamento nos sistemas de ensino para além dos relatos de escravidão (HENRIQUES; CAVALLEIRO, 2005).

Ao discutir a contribuição do Movimento Negro para o pensamento educacional brasileiro, Gomes (1997) sistematiza esse aporte em cinco aspectos: 1) denúncia de que a escola reproduz o racismo presente na sociedade; 2) ênfase na história de lutas e resistência do povo negro; 3) afirmação da existência de um produção cultural negra, que nos remete à África; 4) reconhecimento das diferentes identidades no espaço escolar; e 5) defesa da necessidade de que a estrutura excludente da escola precisa ser reconfigurada para garantir o acesso à educação, à permanência e ao êxito escolar dos alunos de diferentes grupos étnico-raciais e níveis socioeconômicos.

\footnotetext{
${ }^{8}$ A denominação formal é "Programa de Ação Afirmativa do Instituto Rio Branco - Bolsa-

Prêmio de Vocação para a Diplomacia", instituído em 2002 e vigente desde então.

${ }^{9}$ Cf. JACCOUD (2009)
} 


\section{Processo de agendamento}

Kingdon (2014) assevera que o estudo de formação de agenda é um campo de estudo particularmente impreciso. Adverte que temas entram e saem da agenda sem que se saiba precisamente o porquê. A despeito das observações, o autor identifica três formas básicas de um assunto ser incluído em uma agenda governamental: a) via transferência - temas são "transferidos" da agenda sistêmica (não-governamental) para a agenda formal (governamental) por iniciativa do governo ou por pressão política; b) difusão de novas ideias entre as elites profissionais e políticas; c) mudanças no controle do governo e no Legislativo.

O subcampo de estudo sobre formação da agenda (agenda-setting) é constituído por três tradições de pesquisa: agenda da mídia, agenda pública e a agenda política (DEARING; ROGERS, 1992). Entre os estudiosos, não há concordância quanto aos tipos de agenda. Dearing e Rogers (op. cit.) identificam três tipos ou níveis: a) agenda mediática; b) agenda pública; e c) agenda de políticas públicas. McCarthy, Smith e Zald (1996) identificam quatro agendas: 1) pública; 2) dos mass media; 3) governamental; e 4) eleitoral. Esses autores ainda subdividem a agenda governamental em duas: executivo; e legislativo. Por sua vez, Kingdon (2014) distingue os seguintes tipos de agenda: i) "sistêmica" ou não-governamental; ii) governamental; e iii) decisória.

Em que pese às discordâncias quanto aos tipos, três são comuns: agenda dos meios de comunicação (media agenda), agenda pública (agenda sistêmica) e agenda governamental ou de políticas públicas. Em comum, os autores ressaltam a interdependência e a influência mútua entre as agendas.

Como o processo de agendamento resulta da interrelação entre as diferentes agendas, a estratégia dos movimentos sociais, conforme McCarthy, Smith e Zald (1996), é chamar a atenção dos meios de comunicação como forma de alcançar audiências maiores. Pretendem, dessa maneira, acessar as elites governamentais e apresentar suas reivindicações. Nestas disputas políticas para difundir suas mensagens, os movimentos sociais enfrentam ambientes multifacetados e, na maioria das vezes, hostis.

Para analisar o caso em tela, tomo de empréstimo o Modelo de Múltiplos Fluxos (MMF), de Kingdon (2014). Ele fornece marcos de referências e balizas analíticas, para explanar processos de agendamento e formulação de políticas. O modelo destaca a influência das ideias, discursos, interpretações e argumentação no processo político de formulação de políticas públicas (CAPELA, 2007).

\section{Múltiplos Fluxos e Janelas de Políticas Públicas}


Kingdon (2014) concebe a metáfora dos fluxos como recurso explicativo para os processos decisórios em políticas públicas (BIRKLAND, 2015), constatando que os fluxos atravessam governos e processos decisórios. Nesse esforço, Kingdon organiza e rotula a circulação de ideias, atores e processos em três fluxos: fluxo de problemas (problems stream), fluxo de política pública (policy stream) e fluxo da política (politics stream).

No Modelo dos Múltiplos Fluxos (MMF), o processo de produção de políticas públicas assume três propriedades gerais: racionalidade limitada; preferências problemáticas; tecnologias imprecisas; e participação fluida. ${ }^{10}$ Nesse diapasão, governos e processos de produção de políticas públicas operam em ambientes envoltos em incerteza e ambiguidade, nos quais as escolhas são inconsistentes e mal definidas. Estas ajustam-se ao tipo de problema que se quer solucionar, havendo uma grande variação dos atores que participam do processo (trocas constantes dos participantes). Além disso, inexiste relação causal entre uma questão política pública (problema) e a sua solução. O produto resulta da interação entre atores e processos, sem apresentar uma correspondência unívoca.

Cada fluxo movimenta-se de maneira independente um do outro, sobre o qual orbitam inúmeros atores, segundo uma dinâmica peculiar a cada um. Contudo, somente em circunstâncias especiais, quando uma "janela de política pública" (policy window) se abre, os fluxos são reunidos, e a(s) mudança(s) relevante(s) em uma política(s) efetiva(m)-se. Modificações de impacto só ocorrem quando há o acoplamento (coupling) dos três fluxos. Fora desses momentos, é quase impossível que um tema alcance a agenda decisória e se produza um resultado de impacto. Nos acoplamentos, solução encontra problema. Mas a junção dos fluxos não se faz espontaneamente. Empreendedores de políticas (policy entrepreneurs) entram em cena para conectar os três fluxos, efetuando, assim, as alterações na legislação e gerando ou modificando políticas públicas.

Empreendedores de políticas são atores fortemente interessados em uma política. Ser membros do governo não é uma característica essencial. Pode ser um parlamentar, um funcionário da alta burocracia estatal, representante de grupos de interesses ou de instituições de pesquisas, lobistas, ou até mesmo um jornalista influente. Eles se concentram em um problema específico e circulam com desenvoltura nas comunidades e subcomunidades de especialistas de uma determinada política pública. Uma característica marcante é o emprego significativo de recursos (tempo, energia, reputação e, em alguns casos, até dinheiro) para promover as suas propostas preferidas e, assim, acoplar os fluxos, provocando mudanças em uma política. Atuam de modo a convencer os

${ }^{10}$ Cf. Cohen; March; Olsen (1972). 
decisores em relação a um tipo de enquadramento de problema, ao invés de outro. $^{11}$

Uma "janela de política pública" é um momento específico que se descortinar para os atores tentarem aprovar as suas propostas preferidas. Tempo e senso de oportunidade são fundamentais para que a iniciativa logre sucesso. Em geral, uma "janela" se abre e assim permanece por curtos períodos. São passageiras e fugazes. Algumas janelas são previsíveis, outras, não. Há características objetivas que definem uma janela de políticas, e. g., posse de um novo governo, mudanças na composição político-ideológica de uma nova legislatura e algumas fases do ciclo orçamentário. Perdida uma oportunidade, deve-se esperar uma nova chance (KINGDON, 2014).

O fluxo de problema inicia-se quando uma questão ou situação é reconhecida como decorrente do mau funcionamento do sistema sócio-político e ganha o status de problema político. Problemas de políticas públicas não são dados a priori, provêm de sua interpretação (ELDER; COBB, 1984). Situações podem ser interpretadas como problemas por pressão política, com base em indicadores sociais e econômicos; por eventos dramáticos (catástrofes, crises, desastres); ou ainda pelo aumento do conhecimento sobre o funcionamento de programas governamentais via monitoramento e pesquisas de avaliação (KINGDON, 2014). Aqui entra a atuação dos movimentos sociais no sentido de chamar a atenção das elites políticas e burocráticas para sua situação na tentativa de serem reconhecidas como um problema relevante.

Por sua vez, no fluxo de políticas públicas (policy stream) soluções e alternativas são formuladas a todo instante no interior das comunidades de políticas públicas (policy area), e igualmente descartadas. Tempos depois, algumas ideias são recuperadas, aproveitadas e aplicadas (vinculadas) a um problema colocado na agenda. Kingdon (2014) frisa que não existe relação causal entre a existência do problema e formulação da sua solução. Todo o processo é contingencial.

Alternativas de políticas públicas (soluções para problemas) são produzidas nas comunidades de políticas, exempli gratia, saúde, educação, cultura etc. Essas comunidades de especialistas, formadas por pesquisadores, assessores parlamentares, acadêmicos, burocratas do alto escalão, advogados e analistas de grupos de interesses e consultores em planejamento e avaliação de políticas, entre outros. Muitos desses desenvolvem estudos e pesquisas, escrevem artigos em revistas especializadas e na grande imprensa, participam

\footnotetext{
${ }^{11}$ Os empreendedores de políticas agem por diferentes motivações: interesses pessoais, ascensão profissional, aumento de poder burocrático ou político, ampliar o orçamento de seu órgão, também por razões ideológicas e segundo seus sistemas de crenças e valores, Cf. Kingdon (2014).
} 
de debates, ajudam na elaboração de leis, podendo atuar dentro e fora do governo.

Ideias e alternativas de políticas devem circular no interior das comunidades e subcomunidades, a fim de serem conhecidas e passarem pelo escrutínio dos participantes - processo de amaciamento (softening up) -, de modo a engendrar uma convergência nas preferências em torno de uma proposta. Neste fluxo, as ideias prosperam por persuasão.

No fluxo da política (politics stream), um tema tanto pode ser impulsionado quanto obstruído na agenda de decisão. Kingdon (2014) adverte sobre a atuação dos parlamentares, uma vez que, são os únicos que participam integralmente do processo de produção de políticas públicas. A "política pode destacar um assunto, mesmo na ausência de qualquer problema ou solução" (KINGDON, op. cit., p. 202).

Três são os fatores básicos desse fluxo: ciclos eleitorais, oscilações no "humor" nacional e atuação das forças políticas organizadas (grupo de pressão, movimentos sociais, lobbies).

Os ciclos eleitorais acarretam modificações no controle do Executivo e na composição do Legislativo. Temas que antes tinham proeminência na agenda perdem importância, enquanto outros ganham relevância. Trocas de atores em postos-chaves e na base aliada do governo também afetam as agendas governamental e decisória. Oscilações nos governos e nas agendas seguem um padrão randômico que não pode ser replicado ou predito, mas apenas explicado post factum (BIRKLAND, 2007).

Temas da agenda sistêmica alcançam a agenda governamental quando desfrutam, pelo menos, de um "clima" favorável. Essa é uma noção vaga e imprecisa que atende por diferentes rótulos: clima no país, humor nacional, que não são detectados por pesquisas de opinião pública. Dependem da percepção (feelings) de políticos e burocratas envolvidos no processo decisório. Dessa maneira, pontos de uma agenda podem ser promovidos ou sacados, de acordo com a percepção dos atores sobre o "humor nacional". Aqui entra a perspicácia de Kingdon sobre o tempo de uma ideia florescer, isto é, ser aceita como uma solução de política pública. Políticos e burocratas preocupam-se em captar o que seria palatável para os principais formadores de opinião.

As forças políticas organizadas são atores coletivos que desencadeiam ações de apoio ou de oposição a itens da agenda. Exercem pressão sobre o governo e parlamentares. Em certos momentos, a combinação entre "clima nacional" e ciclo eleitoral pode modificar o equilíbrio entre as forças políticas e 
provocar mudanças nas agendas (KINGDON, op. cit.). No fluxo político, negociação e barganha predominam na construção do consenso. ${ }^{12}$

No primeiro governo Fernando Henrique Cardoso, houve modificações na EOP favorável ao Movimento Negro. Em 1995, comemoravam-se os 300 anos da imortalidade do maior líder negro brasileiro, coincidido com o início de novo governo, cujo presidente vinha de uma trajetória acadêmica como sociólogo, na qual investigou o tema das relações raciais, publicando dois livros sobre o assunto, publicando dois livros sobre o tema. O governo contava com a participação de ativistas negros forjados na luta antirracistas, os quais traziam nas suas trajetórias a experiência do Conselho de Participação e Desenvolvimento da Comunidade Negra, do governo do Estado de São Paulo, nos anos de 1984-1990.13 "O GTI, como disse, foi praticamente uma reprodução em larga escala do que a gente fez: era abrir espaço etc. e tal." (ALBERTI; PEREIRA, 2007, p.355). ${ }^{14}$ Sem esquecer que se podia contar como aliados 0 então ministro da Justiça e o secretário de Direitos Humanos.

Nesse período, no campo da educação, três iniciativas merecem menção: a) elaboração dos Parâmetros Curriculares Nacionais, em 1996, e a inclusão da pluralidade cultural como um dos temas transversais, no reconhecimento das diferenças regionais, culturais e raciais, numa tentativa de sua inserção no currículo (SILVA; GUIMARÃES, 2015); b) publicação e distribuição do manual Superando o Racismo na Escola; e c) reconhecimento por parte do Plano Nacional de Direitos Humanos (I e II PNDH) da necessidade de promover uma revisão dos livros didáticos quanto à contribuição da população negra na constituição da identidade nacional, de modo a eliminar estereótipos e discriminações (SILVA, TEIXEIRA; PACÍFICO, 2013).

Lideranças e militantes do Movimento Negro asseveram que o GTI foi fruto da pressão exercida pela Marcha. Em contrapartida, para aqueles que faziam parte do governo, a proposição do GTI já havia sido concebido e seria criado independentemente da Marcha.

Quando a Marcha (...) chegou aqui, deu a impressão de que a Marcha criou o GTI. Mas, na verdade, o GTI já estava pronto. Foi uma coisa construída no governo. Não foi feita pela sociedade. O governo fez e apresentou (ALBERTI; PEREIRA, 2007, P.355). ${ }^{15}$

\footnotetext{
${ }^{12} \mathrm{Na}$ realidade, nem fluxo nem atores têm exclusividade de um modo de ação. Os especialistas não têm o monopólio da persuasão, nem os políticos, o da barganha. A distinção ressalta as diferenças nas dinâmicas dos fluxos (KINGDON, 2014 [1984]).

${ }^{13}$ Consultar Santos, I. (2006) e Hanchard (2001)

${ }^{14}$ Depoimento de Ivair Alves dos Santos (ALBERTI; PEREIRA (2007, p. 355).

15 Depoimento de Ivair Alves dos Santos (ALBERTI; PERERIA, 2007, p. 355).
}

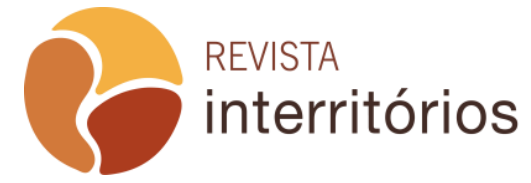


O argumento da disputa de narrativas (RIOS, 2012) não oferece uma explicação para os acontecimentos e a sua sequência e implicações. Não penetra no seu âmago. Qual a relação entre os dois episódios?

Marcha e GTI cumpriram seus papéis ao inscreverem o tema das desigualdades raciais na agenda governamental brasileira, rompendo os limites de uma agenda culturalista a que o tema estava circunscrito. De um lado, a Marcha configurava-se como o fluxo de problema, e, de outro, o GTI simbolizava parte do fluxo da política pública. Ambos se encontraram no Palácio do Planalto no fim da tarde daquele 20 de novembro. Marcha e GTI correram em paralelo até aquele encontro. A Marcha começou a ser organizada no ano anterior. Já as lideranças negras do PSDB traziam a experiência do Conselho de Participação e Desenvolvimento da Comunidade Negra, avaliada como exitosa pelo partido do presidente. ${ }^{16}$

Eis um caso exemplar de solução encontrar o problema. A exemplo de Kingdon (2014) cito Eclesiastes: "Todos os rios vão para o mar, e, contudo, o mar não se enche; ao lugar para onde os rios vão, para ali tornam eles a correr" (BÍBLIA, Eclesiastes 1:7). O fluxo da política não foi conectado durante os dois governos de Fernando Henrique Cardoso (1995-2002). O tema ascendeu à agenda governamental, mas não alcançou a agenda decisória, conotando ausência de empreendedores de políticas para conectar os fluxos e produzir mudanças de impacto.

Na próxima seção, examino alguns aspectos da política de educação para as relações étnico-raciais, assim como seus limites e desafios encetados com a aprovação das Leis 10.639/2003 e 11.645/2008. Examino o plano nacional de implementação das diretrizes nacionais da educação das relações étnico-raciais e para o ensino de história e cultura afro-brasileira e africana. Debato as dificuldades de natureza institucional e política de se implementar uma política nacional em um país federativo e de dimensões continentais, como é o caso do Brasil.

\section{A política de educação para as relações étnico-raciais}

Nos primeiros dias do primeiro Governo do PT houve a aprovação e promulgação da Lei № 10.639, parte de antigas reivindicações do Movimento Negro. Em 09 de janeiro de 2003 aquela foi promulgada pelo presidente da República, uma conquista histórica para o movimento antirracista brasileiro.

Ocorre que o projeto de lei que resultou na Lei oㅜ 10.639/03 tem sua trajetória iniciada em 1986, nas mobilizações em torno da constituinte federal e

${ }^{16}$ Cf. Santos, I. (2006). 
que se espraiaram pelo Brasil após o VIII Encontro de Negros e Negras do Norte e Nordeste. Todavia, somente em 2003 é que os três fluxos foram conectados fluxos de problemas, de política pública e da política. Dessa maneira, a referida lei foi aprovada.

Ainda assim, à época, o texto da lei foi bastante criticado, considerado genérico e sem estabelecer a sua implementação (SANTOS, 2005). Para esse autor, faltava fixar metas, definir um plano de qualificação dos docentes, informar sobre o papel das universidades no atendimento às exigências advindas com a modificação da LDB.

$\mathrm{Na}$ realidade, os detalhes apontados por Santos (op. cit.), todos pertinentes, são definidos quando da regulamentação da lei, via decreto do Poder Executivo. Do Conselho Nacional de Educação (CNE), emanaram as Diretrizes Curriculares Nacionais para a Educação das Relações Étnico-Raciais e para o Ensino de História e Cultura Afro-Brasileira e Africana. Em 2009, o Ministério da Educação elaborou um plano de implementação com metas para qualificação dos docentes entre outras medidas.

As diretrizes curriculares nacionais chamam a atenção de que a alteração na LDB impôs um reexame da política educacional brasileira. Gonçalves e Silva (2013, p. 2) avalia que estamos diante de "uma política de curricular de reconhecimento e de reparação de desigualdades", configurando-se como parte da política de promoção da igualdade racial. No entendimento de Gomes (2009), as mudanças na LDB são parte da luta do direito à educação, acrescido do direito à diferença. Para essa autora (p. 40):

(...), a Lei 10.639/03 e suas diretrizes curriculares possibilitaram uma inflexão na educação brasileira. Elas fazem parte de uma modalidade de política (...). São políticas de ação afirmativa voltadas para a valorização da identidade, da memória e da cultura negras.

As Lei 10.639/ e 11. 645/08 preconizam alterações na política curricular e adentram o interior da instituição escolar, na medida em que exige uma mudança de conduta e de atitude dos membros da comunidade escolar em todos os seus segmentos. O objetivo é fazer com que se reconheça que o racismo antinegro estrutura as relações sociais e afeta o ensino-aprendizagem. A nova política curricular busca rasurar as práticas racistas na instituição escolar.

Não sem razão, a política da educação das relações étnico-raciais desnuda o modelo único de escola, seus processos de hierarquização dos conhecimentos curriculares e as "dificuldades frequentes de pessoas de diferentes pertencimentos étnico-raciais, notadamente brancos e negros, indígenas e não-indígenas conviverem em relações de igualdade e respeito" (GONÇALVES E SILVA, p. 2). 


\section{Inovação institucional e o plano de implementação da política}

Na esteira da aprovação da lei, o MEC criou, no ano seguinte, a Secretaria de Alfabetização, Educação Continuada e Diversidade (SECAD) ${ }^{17}$ para atuar como agente articulador das demais secretarias daquele ministério, de modo a garantir a inclusão de temas como, gênero, raça, etnia, idade e sexualidade nas agendas das demais secretarias do MEC. À SECAD cabia desenvolver programas e ações que envolvessem alfabetização, educação do campo, educação de jovens e adultos, educação escolar indígena, educação quilombola, em direitos humanos, ambiental e educação especial. A ela também competia ações de cooperação técnica e financeira com os Estados, Municípios e Distrito Federal nas áreas citadas, entre outras atribuições. ${ }^{18}$

Segundo o MEC, a Secad constitui uma inovação institucional, pois permite reunir os programas de alfabetização e educação de jovens e adultos, as coordenações de educação indígenas, de educação do campo e educação ambiental, possibilitando articular programas de combate à discriminação racial e sexual com projetos de valorização da diversidade étnica (Brasil, 2004)

Entre 2004 e 2005, a infante secretaria atuou com sofreguidão. Realizou eventos regionais e estaduais para divulgar as Diretrizes Curriculares Nacionais para a Educação das Relações Étnico-Raciais e para o Ensino de História e Cultura Afro-Brasileira e Africana. Iniciou também um diálogo com a sociedade civil fomentando a criação de Fóruns Estaduais de Educação e Diversidade Étnico-Racial. ${ }^{19}$

Um plano só não basta para implementar uma política

No intuito de expandir o diálogo com a sociedade civil e outros atores responsáveis pela implementação da Educação das Relações Étnico-Raciais e o Ensino de História e Cultura Afro-Brasileira e Africana, o MEC, a partir de 2007, encorajou Estados e Municípios a criarem os Fóruns Estaduais e Municipais de Educação e Diversidade Étnico-Racial, como espaços de encontro entre o poder público e a sociedade civil, com o objetivo de divulgar as Diretrizes Curriculares Nacionais (BRASIL, 2013). Espaços para "tecer parcerias, propor caminhos e políticas, acompanhar, auxiliar e congregar todos aqueles que são indispensáveis à implementação da temática das relações étnico-raciais" (BRASIL, 2013, p. 18).

17 Em 2011, a denominação foi alterada para Secretaria de Educação Continuada,

Alfabetização, Diversidade e Inclusão Educacional (SECADI). Foi extinta em janeiro de 2019.

${ }^{18}$ Cf. Decreto n. 7.690 , de 2 de março de 2012.

${ }^{19}$ Cf. Rosa; Midlej (2012). 
Imbuído desse propósito, o MEC reestruturou e ampliou esses fóruns, obtendo plena adesão dos Estados. Em fins de 2008, todos os Estados e o Distrito Federal, com exceção de Roraima, criaram fóruns estaduais (ROSA; MIDLEJ, 2012). Todavia, não logrou o mesmo êxito nos Municípios, vez que os resultados foram bastante modestos (GOMES, 2012). ${ }^{20}$ Rosa (2012, p. 82) aponta que em 2012 já havia sinais evidentes de "desmobilização e desarticulação". Se em "muitos dos Fóruns estaduais e municipais, que até 2010 se encontravam articulados," (Id. Ibid., loc. cit.), dois anos depois, muitos deles foram considerados desativados pela SECADI.

Anos antes, em fins de 2005, o MEC instituíra a Comissão Técnica Nacional de Diversidade para Assuntos Relacionados à Educação dos AfroBrasileiros (CADARA) ${ }^{21}$, com a função de assessorar o MEC nos assuntos relativos à igualdade racial no campo educacional e também poderia sugerir ações afirmativas e para implementação da lei, bem como atuar no seu acompanhamento (BRASIL, 2013). A comissão era composta por representantes do MEC, de outros órgãos federais, estaduais e municipais, e indicados pela sociedade civil. Nas palavras de uma das participantes, "a comissão atua como observatório nacional. Funcionamos como aliados do governo nas questões de diversidade racial". ${ }^{22}$

No esforço de alavancar a implementação, o MEC lança, em 2009, o Plano Nacional de Implementação das Diretrizes Curriculares Nacionais da Educação das Relações Étnico-Raciais e para o Ensino de História e Cultura Afro-Brasileira e Africana, com o qual pretendia que os sistemas de ensino cumprissem as determinações legais referentes de enfrentamento das "diferentes formas de preconceito racial, racismo e discriminação racial para garantir o direito de aprender e a equidade educacional, a fim de promover uma sociedade mais justa e solidária." (BRASIL, 2013, p. 19).

O Plano nacional assentava-se em seis eixos estratégicos: 1) fortalecimento do marco legal; 2) política de formação de gestores e profissionais da educação; 3) política de material didático e paradidático; 4) gestão democrática e mecanismos de participação social; 5) avaliação e monitoramento; 6) condições institucionais.

Para cada eixo estratégico, foram estabelecidas metas, definidos períodos de execução (curto, médio ou longo prazo) e identificados os atores institucionais para a sua consecução; descortinando um emaranhado complexo de redes e articulações políticas nas três esferas de governo, envolvendo: Ministério da Educação (MEC); Coordenação de Aperfeiçoamento de Pessoal

20 Não há dados sistematizados sobre o número de fóruns municipais instituídos.

${ }^{21}$ Extinta pelo Decreto 9759/2019. Todavia, só há registros de seu funcionamento até 2013. Cf. http://etnicoracial.mec.gov.br/noticias/10-menu-principal/112-cadara.

${ }^{22}$ Cf. em http://portal.mec.gov.br/busca-geral/202-noticias/264937351/7962-sp-1970448005. 
de Nível Superior (CAPES); Instituto Nacional de Estudos e Pesquisas Educacionais (INEP); Fundo Nacional de Desenvolvimento da Educação (FNDE); SEPPIR, Fórum Intergovernamental de Promoção da Igualdade Racial (FIPIR); Fundação Cultural Palmares (Ministério da Cultura); Secretarias Estaduais e Municipais de Educação; Ministérios Públicos Estaduais; Conselho Nacional de Educação; Conselhos Estaduais e Municipais de Educação; Comissão de Educação da Câmara Federal; associações de classe como o Conselho Nacional de Secretários de Educação (CONSED) e a União Nacional dos Dirigentes Municipais de Educação (UNDIME), Núcleos de Estudos AfroBrasileiros (NEABs), vinculados a instituições de ensino superior públicas e privadas; a Associação de Brasileira de Pesquisadores Negros (ABPN), além dos Fóruns de Educação e Diversidade; organizações da sociedade civil e de movimentos sociais.

O MEC é o agente indutor da política. Esse ministério executou inúmeras ações direcionadas à implementação das Leis 10.639/03 e 11.645/08. Por exemplo, impressão e distribuição de "um milhão de exemplares das Diretrizes Curriculares Nacionais da Educação das Relações Étnico-Raciais", em 2005, para "todos os sistemas de ensino" (BRASIL, 2013, p. 13), também disponibilizadas na internet, no site domínio público; divulgação e distribuição em larga escala do livro "Orientações e ações para educação das relações étnicoraciais", em 2006; prestação de assistência técnica e financeira na formação continuada de professores da educação básica; apoio financeiro à produção de material didático sobre a temática; desenvolvimento do programa UNIAFRO (2005-2011), investimento de mais de 12 milhões de reais, que, entre 2008 a 2010, promoveu formação para cerca de nove mil profissionais da educação em todo o Brasil (BRASIL, 2013); financiamento da tradução e adaptação da coleção "História Geral da África", produzida pela UNESCO, tendo distribuído oito mil volumes para diversas instituições educacionais. Sem mencionar outras ações, como o incentivo e apoio à realização de pesquisas, seminários e publicações acadêmicas.

Um dos problemas enfrentados na execução do plano foi além da miríade de atores, a questão federativa. No federalismo brasileiro, os Municípios gozam de autonomia política, administrativa e financeira. Não são, portanto, obrigados a seguir programas formulados pelo governo federal. Todavia, no caso específico da Educação das Relações Étnico-Raciais e para Ensino de História e Cultura Afro-Brasileira e Africana, não se trata de uma opção, mas da nãoexecução da Lei de Diretrizes e Bases da Educação Brasileira, Lei no 9394/1996.

Sem dúvida, o MEC envidou esforços, de modo a "(...) transformar as ações e programas de promoção da diversidade e de combate à desigualdade racial na educação em políticas públicas de Estado" (BRASIL, 2013, p. 21). Entretanto, observa-se que o referido plano, apenas poderia recomendava que os Municípios, em seus sistemas, deveriam cumprir o disposto na LDBEN (Lei 
9394/96), e fomentava-os a criarem os fóruns de educação e diversidade étnicoracial (BRASIL, 2009).

A adesão para constituição dos fóruns era voluntária. Se, por um lado, houve um engajamento na criação de fóruns estaduais, por outro, o envolvimento municipal foi pífio. A explicação plausível para esse fenômeno é a ausência de uma estrutura de incentivos suficientemente atraente para instar as prefeituras a criarem essas instâncias de participação.

Cabe notar que alguns Municípios aprovaram Diretrizes Curriculares Municipais de modo a regulamentar a lei federal e adequar-se ao previsto nas Diretrizes Curriculares Nacionais para a Educação das Relações Étnico-Raciais e para o Ensino de História e Cultura, mas não implantaram os Fóruns Municipais de Educação e Diversidade Étnico-Racial, como preconizava o Plano Nacional. Como exemplos, podemos citar Belo Horizonte, Recife e Salvador. ${ }^{23}$

Em uma mirada no plano, observa-se que, das 49 metas, 30 são de curto prazo, das quais seis delas são simultaneamente de curto e médio prazo. Chamam a atenção os tênues mecanismos de acompanhamento. Na medida em que não há quantificação das metas, inexistem elementos tangíveis para aquilatar a implementação.

Por exemplo, na meta 1 do Eixo Fortalecimento do Marco Legal prevê a incorporação dos conteúdos previstos nas Diretrizes Nacionais Curriculares no Plano Nacional de Educação (PNE 2014-2024)24, e igualmente, nos planos estaduais e municipais de educação. O PNE faz referência explicita às Leis 10.639/03 e 11.645/08, na sua estratégia que diz respeito à qualidade da educação básica. Entretanto, o PNE apenas reproduz o disposto nas leis, "sem aprofundar a formas de como fará a implementação dos conteúdos previstos nelas nos currículos escolares" (FRANÇA, 2015, p. 8). Para essa autora, a temática étnico-racial aparece de maneira acanhada e superficial nas metas. Além disso, o PNE não contempla os aspectos prioritários das Leis 10.639/03 e 11.645/08 que dizem respeito à política curricular.

A análise do plano revela problemas e dificuldades inerentes de implementação de políticas em Estados federativos. A questão federativa é uma variável importante para se compreender os óbices relativos à implementação de políticas públicas nessa forma de Estado.

$\mathrm{Na}$ forma federativa, as entidades territoriais que a integram gozam de autonomia política, financeira e administrativa, podendo ser duas ou mais esferas de poder político (COSTA, 2010). No caso brasileiro, a Constituição reconhece três instâncias de poder político: União, Estados e Municípios.

${ }^{23}$ Cf. Guimarães (2018).

${ }^{24}$ O PNE foi aprovado pelo Congresso Nacional em junho de 2014, cf. Lei № 13.005. 
O governo federal desempenha o papel indutor e coordenador das políticas em todo o território nacional, inclusive corrigindo distorções e desigualdades na capacidade de gastos e de gestão dos governos subnacionais (ARRETCHE, 2004). As ações da União devem se pautar segundo dois dos quatro princípios básicos do federalismo: subsidiariedade e equidade federativa (cf. COSTA, op. cit.).

Nesse diapasão, o governo federal deve esboçar um modelo e uma agenda que incentive a adesão de Estados e Municípios à política a ser implementada. Para tanto, faz-se necessário que o governo federal delineie mecanismos institucionais capazes de atrair, constranger e incentivar a adesão das subunidades da Federação à política ou programa. ${ }^{25}$ Do contrário, as ações não surtirão os efeitos esperados, ou seja, a aquiescência dos Estados e Municípios.

Qualquer avaliação da política em tela deve levar em conta que ela tem diante de si a tarefa hercúlea de realizar uma mudança institucional complexa. Além de reformar um sistema de política pública consolidado - como é o caso da educação -, a política de igualdade racial exige transformações nos níveis mais profundos de crenças e valores de autoridades, técnicos e servidores dos níveis mais elementares da instituição escolar, no que tange à concepção e percepção secularmente construída em relação às populações negra e indígena. O seu maior desafio é a desconstrução do racismo existente nas relações sociais, nos níveis micro e macro. Assim, é preciso atentar para o fato de que por não constituir em um subsistema da política educacional, como a educação básica, o ensino superior ou a política de financiamento, mas um tema transversal, a educação das relações raciais é deslocada para um lugar secundário ou mesmo marginal na agenda do MEC. Com efeito, os de instrumentos mais efetivos de indução não são acionados.

\section{CONSIDERAÇÕES FINAIS}

A Constituição de 1988 reconheceu a pluralidade étnico-racial e a diversidade cultural da população brasileira, efeito das lutas dos movimentos sociais negro e dos povos indígenas ao longo de décadas. Entretanto, a subalternização dos não-brancos continua a reger e estruturar as relações sociais. Desse modo, pluralidade e diferença ainda operam sob os signos da desigualdade e opressão.

O racismo e a discriminação racial até pouco tempo figuravam como questões de natureza interpessoal, igualmente seu equacionamento. Antípoda a esta interpretação, enfatizei as dimensões político-institucionais. Nesse esforço,

25 Cf. Arretche $(1999,2000,2004)$ COSTA $(2007,2010)$. 
descrevi a trajetória recente do Movimento Negro pelo reconhecimento do racismo como um problema político. A reconstituição desse itinerário das mobilizações fazia-se mister para demonstrar que a formação da agenda governamental é um processo complexo, desordenado e não-linear (ELDER; COOB, 1984), afastando explanações assentadas na vaga noção de "vontade política".

Evidencie que a ascensão do tema da igualdade racial na agenda governamental decorreu da confluência de três episódios fundamentais: Marcha 300 anos de Zumbi, criação do GTI e realização da 3⿳亠丷厂 CMR. Ressaltei que durante os governos $\mathrm{FHC}$, apesar de o tema ter alcançado a agenda, não produziu alterações significativas no curso das políticas. Chamei a atenção para o fato de as conexões dos fluxos terem ocorrido no governo Lula não derivaram de mera "vontade política", mas de, parafraseando Kingdon, ter chegado o tempo de uma ideia florescer.

O MEC atuou no sentido de disseminar informações, como a produção e distribuição das Diretrizes Curriculares Nacionais, manuais e livros, entre outras ações, no entanto, o sucesso da implementação depende, em muito, da adesão dos entes federativos, e, no caso da política em tela, dos profissionais da educação.

A literatura aponta que após uma fase de mobilização, confrontação, e atendimento de certas reivindicações, os movimentos sociais tendem a desmobilizar-se (TARROW, 2009). Esse autor assinala que, "é raro encontrar uma narrativa teorizada que explique por que um ciclo ascende inexoravelmente até certo ponto e depois, com a mesma certeza, declina" (p. 188). A explicação mais simples é o da exaustão. Conquistas, mesmo que parciais se fazem acompanhar concomitantemente de "cansaço e desilusão. Disso resulta um declínio na participação (...)” (p. 189).

O debate e a proposição de políticas de igualdade racial emergiriam em um contexto de avanço do neoliberalismo. Uma das críticas a elas dirigidas era de que se tratava de políticas focalizadas, ferindo, assim, um suposto princípio do universalismo abstrato, alicerçada em uma perspectiva de cidadania talqualmente abstrata, que historicamente excluiu não-brancos, em benefício do segmento branco. Ora, o caso brasileiro, põe em xeque a absolutização da dicotomia entre políticas universais versus políticas focais. Ora, tais políticas quando destinadas a negros e indígenas, maioria da população, assume características universalizantes. A mescla entre essas variantes de políticas parecer ser promissora como mecanismo de correção das persistentes desigualdades sócio-raciais.

Por fim, mas não menos importante, segundo Avritzer (2016), o golpe político-midiático concretizado no impeachment da presidente Dilma Roussef simboliza o fim da Nova República e sua agenda progressista de compromisso 
de inclusão social (promessa não realizada). Desde então, a agenda da igualdade racial cedeu espaço para a das reformas pró-mercado, descompromissada com qualquer ideal de igualdade.

\section{REFERÊNCIAS}

ALBERTI, Verena; PEREIRA, Amilcar A. (Orgs.). História do movimento negro no Brasil: depoimentos ao CPDOC. Rio de Janeiro: Pallas; CPDOC-FGV, 2007.

ALONSO, Angela; COSTA, Valeriano; MACIEL, Débora. Identidade e estratégia na formação do movimento ambientalista brasileiro. In: LUCHMANN, L. H. H.; SELL, C. E.; BORBA, J. (Orgs.). Movimentos sociais, participação e reconhecimento. Florianópolis: Fundação Boiteux, p. 21-45, 2008.

ARRETCHE, M. Federalismo e políticas sociais no Brasil: problemas de coordenação e autonomia. São Paulo em Perspectiva, São Paulo, v. 18, n.2, p. 17-26, 2004.

ARRETCHE, M. Estado federativo e políticas sociais: determinantes da descentralização. Rio de Janeiro: Revan; São Paulo: FAPESP, 2000.

ARRETCHE, M. Políticas sociais no Brasil: descentralização em um Estado federativo. Revista Brasileira de Ciências Sociais, São Paulo, vol.14, n. 40, p. 111-141, jun. 1999.

AVRITZER, Leonardo. Sociedade civil e democratização. Belo Horizonte: Del Rey Editora, 1994.

AVRITZER, Leonardo. O fim da Nova República. Jornal GGN. Disponível em https://jornalggn.com.br/analise/o-fim-da-nova-republica-por-leonardo-avritzer/. Acesso em: 18 de março de 2020.

BATISTA. M $M^{a}$ de F. O. A emergência da lei $10.639 / 03$ e a educação das relações étnico-raciais em Pernambuco [Dissertação de mestrado]. Recife: Centro de Educação da UFPE, 2009.

BíBLIA, A. T. Eclesiastes. In: BíBLIA. Português. A Bíblia Sagrada: Antigo e Novo Testamentos. London: Sociedade Bíblica Trinitariana do Brasil, 2011. p. 737.

BIRKLAND, Thomas A. Agenda Setting in Public Policy In: FISCHER, F.; MILLER G. J.; SIDNEY, M. S. (Eds). Handbook of public policy analysis: theory, politics, and methods. Boca Raton, FL: CRC Press, 2007, p. 63-78.

BIRKLAND, A. T. An introduction to the policy process: theories, concepts, and models of public policy making. 3rd. New York: Routledge, 2015.

BRASIL. Lei no 9.394, de 20 de dezembro de 1996. Lei de Diretrizes e Bases da Educação Brasileira. Disponível em: http://www.planalto.gov.br/ccivil_03/leis//9394.htm. Acesso em: 15 mar. 2020.

BRASIL. Ministério da Justiça. Programa Nacional dos Direitos Humanos. Brasília, 1996. 
BRASIL. Ministério da Justiça. Programa Nacional dos Direitos Humanos II. Brasília, 2002

BRASIL. Lei no 10.639, de 9 de janeiro de 2003. Altera a Lei № 9. 394, de 20 de dezembro de 1996. Disponível em

http://www.planalto.gov.br/ccivil_03/leis/2003/110.639.htm. Acesso em: 15 de mar. 2020.

BRASIL. Diretrizes Curriculares Nacionais para a Educação das Relações ÉtnicoRaciais e para o Ensino de História e Cultura Afro-Brasileira e Africana. Brasília, 2004.

BRASIL. Ministério da Educação. Secad. Documento de apresentação da Secretaria de Educação Continuada, Alfabetização e Diversidade (Secad). Brasília, 2004.

BRASIL. Lei no 11.645/08, de 10 de março de 2008. Altera a Lei no 9.394, de 20 de dezembro de 1996. Disponível em http://www.planalto.gov.br/ccivil_03/_Ato20072010/2008/Lei/L11645.htm. Acesso em: 15 de mar. 2020

BRASIL. Ministério da Educação. Plano Nacional de Implementação das Diretrizes Curriculares Nacionais da Educação das Relações Étnico-Raciais e para o Ensino de História e Cultura Afro-brasileira e Africana. Brasília, nov. de 2009.

BRASIL. Decreto n. 7.690, de 2 de março de 2012. Aprova a Estrutura Regimental e o Quadro Demonstrativo dos Cargos em Comissão e das Funções Gratificadas do Ministério da Educação. Disponível em https://www2.camara.leg.br/legin/fed/decret/2012/decreto-7690-2-marco-2012-612507norma-pe.html. Acesso em: 23 de nov. 2019.

BRASIL. Plano Nacional de Implementação das Diretrizes Curriculares Nacionais para a Educação das Relações Étnico-Raciais e para o Ensino de História e Cultura Afro-Brasileira e Africana. Ministério da Educação, Secretaria de Educação Continuada, Alfabetização, Diversidade e Inclusão. Brasília: MEC, SECADI, 2013.

BRASIL. Lei $\mathbf{n}^{\circ} \mathbf{1 3 . 0 0 5}$, de 25 de junho de 2014. Aprova o Plano Nacional de Educação - PNE e dá outras providências. Disponível em https://www2.camara.leg.br/legin/fed/lei/2014/lei-13005-25-junho-2014-778970publicacaooriginal-144468-pl.html>. Acesso em: 10 de nov. 2019.

CADARA. Educação para Relações Étnico-Raciais. Notícias. Disponível em http://etnicoracial.mec.gov.br/noticias/10-menu-principal/112-cadara. Acesso em 10 de nov. 2019.

CAPELLA, Ana C. N. Perspectivas Teóricas sobre o Processo de Formulação de Políticas Públicas. In: HOCHMAN, Gilberto; ARRETCHE, Marta; MARQUES, Eduardo (Orgs.). Políticas Públicas no Brasil. Rio de Janeiro: Fiocruz, 2007, p. 87-122.

CONSELHO Nacional de Educação/Conselho Pleno (CNE/CP). Resolução № 1, de 17 de junho de 2004. Disponível em http://portal.mec.gov.br/cne/arquivos/pdf/res012004.pdf. Acesso em: 05 de nov. 2019. 
COSTA, Valeriano M. F. Federalismo e relações intergovernamentais: implicações para a reforma da educação no Brasil. Educação \& Sociedade (Impresso), v. 31, p. 729-748, 2010.

COSTA, Valeriano M. F. Federalismo. In: AVELAR, L.; CINTRA, A. O. (Orgs.).

Sistema político brasileiro: uma introdução. 2ed. Rio de Janeiro: Konrad-AdenauerStiftung; São Paulo: Unesp, 2007.

DEARING, James. W.; ROGERS, Everett M. Communication Concepts 6: Agendasetting. Thousand Oaks, CA: Sage. 1992.

EISINGER, Peter K. The conditions of protest behavior in American cities. American Political Science Review, v. 67, n. 1, 1973, p. 11-28. Disponível em http://www.jstor.org/stable/1958525. Acesso em: 5 de nov. de 2015.

ELDER, Charles; COBB, Roger. Agenda-Building and the Politics of Aging. Policy Sciences Journal, v. 13, n. 1, 1984.

FERNANDES, Florestan. A integração do negro na sociedade de classes. $5^{\underline{a}}$ ed. São Paulo: Ática, 2008 [1964]. Edição digital.

FRASER, Nancy. Da redistribuição ao reconhecimento? dilemas da justiça na era póssocialista. In SOUZA, J. (Org.). Democracia Hoje: novos desafios para a teoria democrática contemporânea, Brasília, Editora UnB, 2001, p. 245-282.

FRASER, Nancy. Reconhecimento sem ética? Lua Nova, São Paulo, n. 70, p. 101 138, 2007. Disponível em:scielo.br/pdf/ln/n70/a06n70. Acesso em: 20 set. 2013.

GAMSON, William A.; MEYER, David S. Framing political opportunity. In: McADAM, D.; McCARTHY, J.; ZALD, M. (Eds.). Comparative perspectives on social movements: political opportunities, mobilizing structures, and cultural framings. Cambridge University Press, 1996, p. 275-290.

GOMES, Nilma L. (Org). Práticas Pedagógicas de Trabalho com Relações ÉtnicoRaciais na Escola na Perspectiva da Lei 10.639/03. Brasília: MEC; UNESCO, 2012.

GOMES, Nilma L. A Contribuição dos Negros para o Pensamento Educacional Brasileiro. In: GONÇALVES E SILVA, P. B.; BARBOSA, L. M. A. (Orgs.). 0 pensamento negro em educação no Brasil: expressões do movimento negro. São Carlos, SP: Ed. da UFSCar. 1997.

GOMES, Nilma L. Limites e Possibilidades da Implementação da Lei 10.639/03 no Contexto das Políticas Públicas em Educação. In: PAULA, M.; HERINGER, R. (Orgs.). Caminhos Convergentes: Estado e Sociedade na superação das desigualdades raciais no Brasil. Rio de Janeiro: Fundação Heinrich Boll, ActionAid, 2009.

GONÇALVES E SILVA, Petronilha B. Lei oㅜ 10.639/2003 - 10 Anos. Revista Interfaces de Saberes, v. 1, n.13, p. 1-13, 2013.

GUIMARÃES, Carlos A. S. Movimento negro e mudança institucional no Brasil: políticas municipais de promoção da igualdade racial em perspectiva comparada (1995-2015). [Tese de Doutorado]. Instituto de Filosofia e Ciências Humanas da Unicamp, São Paulo, 2018. 
HANCHARD, Michael. Orfeu e o poder: o Movimento Negro no Rio de Janeiro e São Paulo (1945-1988). Rio de Janeiro: UERJ, 2001.

HASENBALG, Carlos A. Comentários Raça, cultura e classe na integração das sociedades. Rio de Janeiro, Dados, Revista de ciências sociais. v. 27, n.3, p. 148-149, 1984.

HENRIQUES, Ricardo: CAVALLEIRO, Eliane. Educação e políticas públicas afirmativas: elementos da agenda do Ministério da Educação. In: SANTOS, Sales. A. (org.). Ações afirmativas e combate ao racismo nas Américas. Brasília: Ministério da Educação, Secretaria de Educação Continuada, Alfabetização e Diversidade. 2005, p. 211-227.

HERINGER, Rosana. Políticas de promoção da igualdade racial no Brasil: um balanço do período 2001-2004. In: FERES JÚNIOR, J.; ZONINSEIN, J. (Orgs). Ação afirmativa e universidade: experiências nacionais comparadas. Brasília: UnB, 2006, p. 79-109.

HOLSTON, James. Cidadania insurgente: disjunções da democracia e da modernidade no Brasil. São Paulo: Companhia das Letras 2013.

IBGE - Instituto Brasileiro de Geografia e Estatística (2010). Pesquisa Nacional por Amostra de Domicílios. Síntese dos Indicadores de 2009. Rio de Janeiro: IBGE; 2010. Disponível em:

http://www.ibge.gov.br/home/estatistica/populacao/trabalhoerendimento/pnad2009/pna d_sintese_2009.pdf. Acesso em: 10 abr 2015.

INSTITUTO RIO BRANCO. Ministério das Relações Exteriores. Programa de Ação Afirmativa. Disponível em http://www.institutoriobranco.itamaraty.gov.br/programa-deacao-afirmativa. Acesso em: 24 nov. 2019.

JACCOUD, Luciana (Org.). A construção de uma política de promoção da igualdade racial: uma análise dos últimos 20 anos. Brasília: Ipea, 2009.

JACCOUD, Luciana de B.; BEGHIN, Nathalie. Desigualdades raciais no Brasil: um balanço da intervenção governamental. Brasília: IPEA, 2002.

KINGDON, John W. Agendas, Alternatives, and Public Policies. 2nd. Essex: Pearson Education, 2014.

MCADAM, Doug. Conceptual origins, current problems, future directions. In: McADAM, D.; McCARTHY, J.; ZALD, M. (Eds) Comparative perspectives on social movements: political opportunities, mobilizing structures, and cultural framings. Cambridge University Press, 1996, p. 23-40.

McCARTHY, John; SMITH, Jackie; ZALD, Mayer. Accessing public, media, electoral, and governmental agendas. In: McADAM, D.; McCARTHY, J.; ZALD, M. (Eds) Comparative perspectives on social movements: political opportunities, mobilizing structures, and cultural framings. Cambridge University Press, 1996, p. 291-311.

Negro e Educação. Relatório do VIII Encontro dos Negros do Norte e Nordeste do Brasil. Recife: Movimento Negro Unificado, 1988. 
NOGUEIRA, Oracy. Preconceito racial de marca e preconceito racial de origem: sugestão de um quadro de referência para a interpretação do material sobre relações raciais no Brasil. Tempo Social, Revista de Sociologia da USP, v. 19, n. 1, p. 287-308, 2006,

PAIXÃO, Marcelo. A Dialética do Bom Aluno: relações raciais e o sistema educacional brasileiro. Rio de Janeiro: Editora FGV, 2008.

PEREIRA, Amaury M. Trajetória e perspectivas do movimento negro brasileiro. Belo Horizonte: Nandyala, 2008.

PINTO, Celi. R. J. Nota sobre a controvérsia Fraser-Honneth informada pelo cenário brasileiro. Lua Nova, São Paulo, n. 74, p. 35-58, 2008.

RIBEIRO, Matilde. Políticas de promoção da igualdade racial no Brasil (19862010). Rio de janeiro: Garamond, 2014.

RIOS, Flávia M. O protesto negro no Brasil contemporâneo. Lua Nova, São Paulo, n. 85, p. 41-79, 2012.

ROSA, Barbara da S. A influência dos fóruns de educação e diversidade étnicoracial na implementação da política de promoção da igualdade racial.

[Dissertação de mestrado]. Faculdade de Economia, Administração, Contabilidade e Ciência da Informação e Documentação da UnB, Brasília, 2012.

ROSA, Barbara da S.; MIDLEJ, Suylan. Fóruns de Educação e Diversidade ÉtnicoRacial: condicionantes legais para a participação social nas políticas públicas educacionais. Pensamento \& Realidade, v. 27, n. 2, p. 79-94, 2012.

SANTOS, Ivair A. A. O Movimento Negro e o Estado (1983-1987): o caso do Conselho de Participação e Desenvolvimento da Comunidade Negra no Governo de São Paulo. São Paulo: Imprensa Oficial, 2006.

SANTOS, Joel Rufino dos. O movimento negro e a crise brasileira. Política e Administração, Rio de Janeiro, no 2. Fundação Escola de Serviço Público/RJ, p. 287306, jul./set. 1985.

SANTOS, Sales Augusto. A Lei no 10639/03 como fruto da luta anti-racista do Movimento Negro. In: MINISTÉRIO DA EDUCAÇÃO. Secretaria de Educação Continuada, Alfabetização e Diversidade. Educação anti-racista: caminhos abertos pela Lei no 10.634/03. Brasília, 2005.

SILVA, Claudilene $M^{a}$. A volta inversa na árvore do esquecimento e nas práticas de branqueamento: práticas pedagógicas escolares em história e cultura afrobrasileira. Curitiba: CVR ,2019.

SILVA, Claudilene $M^{\mathrm{a}}$; GUIMARÃES, Carlos A. S. POLÍTICAS PÚBLICAS E RELAÇÕES ÉTNICO-RACIAIS NO BRASIL: a luta da população negra por reconhecimento e educação. Trabalho apresentado no XXX Congreso de La Associación Latinoamericana de Sociología, San Jose, Costa Rica, 2015.

SILVA, Paulo V. B.; TEIXEIRA; Rozana; PACÍFICO, Tânia M. Políticas de promoção de igualdade racial e programas de distribuição de livros didáticos. Educ. Pesqui. São Paulo, v. 39, n. 1, p. 127-143, jan./mar. 2013. 
TARROW, Sidney. 0 poder em movimento: movimentos sociais e confronto político. Petrópolis, RJ: Vozes, 2009.

TELLES, Edward E. Racismo à brasileira: uma perspectiva sociológica. Rio de Janeiro: Relume Dumará: Fundação Ford, 2003. 